\title{
Oculomotor adaptation to prisms is not simply a muscle potentiation effect
}

\author{
BRIAN CRASKE and MARTIN CRAWSHAW \\ University of Southampton, Southampton SO9 5NH, England
}

\begin{abstract}
An experiment is reported in which subjects pointed to a visual target before and after exposure to prisms. The exposure condition required the subject to look at his feet through leftward deviating prisms while holding his eyes to the right. Aftereffects on pointing were significantly to the right. This result is opposite to that predicted by the muscle potentiation hypothesis put forward by Ebenholtz and Wolfson (1975), but consistent with recalibration of the visual direction system caused by spatial discordance.
\end{abstract}

In recent years, a number of studies on prism adaptation have been published in which the data have been interpreted as supporting the occurrence of a change in registered position of the eye (Craske, 1967; Hay \& Pick, 1966; Templeton, Howard, \& Wilkinson, 1974).

One sommonly held theoretical view maintains that a necessary condition for this and other forms of prism adaptation to take place is that the subject be presented with conflicing spatial information, and that it is the latter which leads to the adaptive shift (Moulden, 1971: Wallach \& Karsh, 1963).

A paper by Ebenholtz and Wolfson (1975) puts forward a quite different possibility. They argue that the prisn-wearing situation could require the subject to hold his eyes to the side of the imposed displacement. This induces an afterdischarge in the original agonist ocular muscles in the postexposure situation. Such an effect they call a "muscle potentiation effect," and they argue that it will bias the subsequent innervation required to direct the eyes. Thus, if the position of the eye in the head is known by monitoring outflow, this predicts the unidirectional errors of visual localization which follow exposure to prisms. On these grounds, Ebenholtz and Wolfson argue that care must be exercised in interpreting the results of prism adaptation as some form of recalibration of the mechanism reading out eye position.

There are a number of lines of evidence which suggest that changes in visual direction after exposure to prisms are for the most part subserved by mechanisms different from those proposed by Ebenholtz and Wolfson.

In the studies to be quoted, the conditions of prism exposure always involve the subject in looking at his feet. This has the merit of restricting adaptive changes and aftereffects to the visual system.

First, although both prolonged lateral deviation of the eyes and prism wearing are associated with a change in visual direction, the aftereffects of the two conditions upon the resting position of the eyes ${ }^{1}$ is quite different. The former aftereffect decays slowly with time, the latter results in prolonged sinusoidal variation in position (Craske, Crawshaw, \& Heron, 1975).

A second observation is that if the subject's eyes are held in the straight-ahead position during exposure, adaptation still takes place (Crawshaw \& Craske, 1974). When viewing through a prism with the eyes in the straight-ahead position, it may be necessary to turn the head to compensate. It is unlikely, however, that this compensation leads to aftereffects, for another experiment requiring a similar exposure produced no evidence for adaptation of registered position of the head on the neck (Crawshaw \& Craske, in press). Finally, lateral deviations of $11.3 \mathrm{deg}$, identical to that due to a 20-diopter prism, were found to have no measurable effect on eye centering after a 10-min treatment period (Craske, 1967).

Although these studies suggest that muscle potentiation is likely to be no more than a minor factor which may sometimes contribute to prism aftereffects, the following experiment was carried out as a direct attack on the problem. The rationale is as follows. The subject is exposed to leftward displacing prisms but is made to turn his eyes to the right while doing so. This situation leads to two opposite predictions. If the subject recalibrates to the discordant spatial information, visually guided localizing will be in error to this right. If the "prism effects" are really due to previous eye posture, aftereffects will be to the left.

\section{METHOD}

\begin{abstract}
Apparatus
A table was built which allowed unobstructed reaching beneath its surface. A dental bite board could be attached at head height. and the height of the subject could be adjusted so that his shoulder was just beneath the undersurface of the table. On the top of the table, a vertical luminous target. $1 \mathrm{~mm}$ wide and $1 \mathrm{~cm}$ high, was mounted $1 \mathrm{~m}$ away from the subject in his median sagittal plane.
\end{abstract}


Table 1

Change in Pointing (Degrees)

\begin{tabular}{crcc}
\hline Subject & \multicolumn{3}{c}{ Subject } \\
\hline 1 & 3.20 & 6 & 2.74 \\
2 & 3.58 & 7 & 2.68 \\
3 & .74 & 8 & 3.44 \\
4 & 2.57 & 9 & 3.91 \\
5 & .18 & 10 & 1.31 \\
\hline
\end{tabular}

Note-Mean $=2.44$

\section{Subjects and Procedure}

Ten right-handed subjects were used in a test, treatment, retest design, with the laboratory in darkness. Each subject was required to make 10 judgments of the direction of the line, using his right arm to make a mark with a fiber-nib pen on a scale beneath the tabletop. The subject then underwent an exposure condition which used a pair of horizontally mounted $20 \mathrm{D}$ base-right prisms. He was asked to stand upright with his feet together, incline his head forward, and inspect his feet via prisms for $6 \mathrm{~min}$; only his feet were in sight. During the exposure, the subject's head was turned through $25 \mathrm{deg}$, chin towards left shoulder, and this position was controlled by a bite bar. This arrangement produced an average deviation of the subject's eyes of $13.7 \mathrm{deg}$ to the right; free inspection of the feet affected this by about $\pm 2 \mathrm{deg}$.

Immediately after the exposure period, the subject was repositioned and asked to make a further 10 judgments of the direction of the line.

\section{RESULTS}

There was a significant mean shift of pointing to the right of $2.44 \mathrm{deg}, \mathrm{t}(9)=6.07, \mathrm{p}<.001$. All subjects showed this shift.

\section{DISCUSSION}

These results suggest that the primary mechanism responsible for adaptation to prisms is not based upon the muscle potentiation effect; if it were, the opposite results would have been obtained. The results, however, are predicted on the basis of a recalibration of visual direction in order to minimize the imposed, discordant, sensory-sensory spatial information.
There is no doubt that previous eye position can affect both eye centering and visually guided reaching (Craske, Crawshaw, \& Heron, 1975), and to this extent it is reasonable to say that it may be an independent, but minor, factor which contributes to prism aftereffects. However, both these results and the other evidence cited indicate that muscle potentiation is unlikely to play a more important role.

\section{REFERENCES}

CRASKE, B. Adaptation to prisms: Change in internally registered eye position. British Journal of Psychology, 1967, 58, 329-335.

Craske, B., Crawshaw, M., \& Heron, P. Disturbance of the oculomotor system due to lateral fixation. Quarterly Journal of Experimental Psychology, 1975, 27, in press.

Crawshaw, M., \& Craske, B. No retinal component in prism adaptation. Acta Psychologica, 1974, 38, 421-423.

Crawshaw, M., \& Craske, B. Oculomotor adaptation to prisms: Complete transfer between eyes. British Journal of Psychology, in press.

Ebenholtz, S. M., \& Wolfson, D. M. Perceptual after-effects of sustained convergence. Perception \& Psychophysics, 1975, 17. 485-491.

HAY, J. C., \& Prck, H. L. Visual and proprioceptive adaptation to optical displacement of the visual stimulus. Joumal of Experimental Psychology, 1966, 71, 150-158.

Moulden, B. Adaptation to displaced vision: Reafference is a special case of the cue-discrepancy hypothesis. Quarterly Journal of Experimental Psychology, 1971, 23, 113-117.

Templeton, W. B., Howard, I. P., \& Wilkinson, D. A. Additivity of components of prismatic adaptation. Perception \& Psychophysics, 1974, 15, 249-257.

WallaCh, H., \& Karsh, E. B. The modification of stereoscopic depth-perception and the kinetic depth effect. American Journal of Psychology, 1963, 76. 429-435.

\section{NOTE}

1. The resting position has been operationally defined as the position adopted by the eye when the eyelids are opened, no voluntary eye positioning movements are made, and the subject's visual field is cueless and homogeneous (Craske, Crawshaw, \& Heron, 1975).

(Received February 28, 1975; revision received April 29, 1975.) 